\title{
Authentic leadership and employee engagement: The role of employee well-being
}

\author{
Vui-Yee Koon* and Tsu-Sin Ho \\ Department of Management, Sunway University, Selangor, Malaysia
}

Received 9 March 2020

Accepted 17 May 2020

\begin{abstract}
. relational perspective. Twitter data. people in social media. work engagement

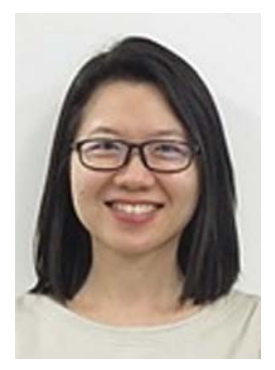

Vui-Yee Koon is a Senior Lecturer in the Department of Management at Sunway University. Her research interests include strategic human resource management, industrial organisational psychology and humanistic management. Much of her research work focus has been on improving employee performance regarding job attitude and behaviour.
\end{abstract}

BACKGROUND/OBJECTIVE: To understand how perceived authentic leadership translates into work engagement, this study hypothesize that perceived authentic leadership facilitates positive conditions of well-being, which in turn predict employee work engagement. This study asserts that each of the three mediating paths comprising life, workplace, and psychological well-being, is expected to mediate the relationship based on the conservation of resources (COR) theory and

METHODOLOGY: Data were collected from the two-wave survey of 150 full-time employees and analyzed using the PROCESS macro in SPSS. An additional analysis to identify well-being sentiment was conducted using NodeXL with

RESULTS: The results indicated only workplace well-being has a mediational effect between perceived authentic leadership and work engagement. The additional analysis found that workplace well-being is the central tenet of interaction between

CONCLUSIONS: These findings demonstrate the importance of workplace well-being in promoting work engagement.

Keywords: Authentic leadership, life well-being, workplace well-being, psychological well-being, conversation of resources,

\footnotetext{
${ }^{*}$ Corresponding author: Vui-Yee Koon, Department of Management, Sunway University, No. 5, Jalan Universiti, Bandar Sunway, 47500 Subang Jaya, Selangor, Malaysia. E-mail: vuiyeek@gmail.com.
}

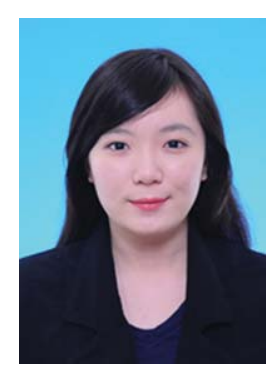

Tsu-Sin Ho is a graduate of Sunway University. She has always interested to explore the factors determine a positive working ethics and thus drives her interest in researching the corporate workforce and factors that influence work attitude.

\section{Introduction}

Leadership marks the survival or downfall of an organization [28]. Leaders who treat their employees authentically are an important component of effective leadership [33]. Authentic leaders bring hope, trust, 
confidence, transparency, positive emotions, and an ethical and moral heading towards the future [3]. Past studies suggested that authentic leadership may positively affect employee attitudes and behaviours such as job satisfaction, engagement, commitment and trust, (e.g. $[10,46]$ through their genuine works and actions. While the relationship of authentic leadership with employee attitudes and behaviours is relatively well-established, it is still unclear how authentic leaders influence employee behaviour such as engagement [41].

Some literatures suggested that leaders with authenticity attributes may contribute to employee well-being (e.g. [62], but only a few has looked at the effects of authentic leadership on employee well-being [45]. Rather than having a narrow view of employee well-being, it is advisable to look at multi-dimensional employee well-being and each dimension needs to be studied separately [66] in relation to leadership. The effects of authentic leadership in the workplace can result in trade-offs between the dimensions of well-being, which may strengthen and weaken the level of engagement among employees. In order for authentic leadership to have this effect, action of the leader's actions should be perceived as authentic by the employees [24]. Employee positive perception of leadership style can lead to positive employee behavior (cf. [67]).

Most empirical studies promote the importance of employee well-being and work attitudes such as job satisfaction, but limited study on work behaviours such as engagement [27] although the idea of engaging employees in the workplace is increasingly important (cf. [1]). Using the conservation of resources (COR) and relational perspectives as underpinning theories, this current study investigates if multi-dimensional employee well-being influence the relationship between perceived authentic leadership and employee work engagement. The conservation of resources (COR) theory explains that individuals experience stress due to loss of resources and are thereby motivated to seek, defend, and protect their resources [22]. Stress is also related to environmental and cognitive perspectives. In other words, when employees assume that their resources are threatened or lost due to leadership issues [55] such as receiving less supervisory support [32, 37], they may view their work experience negatively. From the relational perspective, the activities that are carried out must be seen as consistent and establish a relationship pattern that improve work behaviour [57]. This links to COR theory whereby consistency

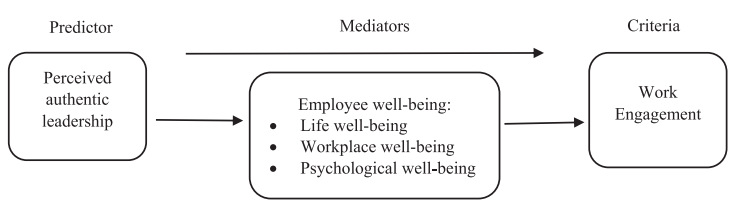

Fig. 1. The current study's proposed model.

in employees' perception of available resources catering to their well-being in an organization facilitates the authentic leadership-work engagement process. The consistent perception that employees' well-being is being provided for by authentic leaders reduces loss of resources, which in turn, increases work engagement.

Hence, the current study proposes a model (see Fig. 1) linking authentic leadership as perceived by employees to work engagement via the three dimensions of employee well-being - life, workplace, and psychological. Findings from the current study are expected to provide a richer understanding regarding the underlying mechanism linking authentic leadership and work engagement. The current study seeks to answer the following research question:

$R Q$ : Will multifaceted of employee well-being affect their perceived authentic leadership-work engagement relationship?

\section{Literature review and hypotheses development}

\subsection{Perceived authentic leadership and work engagement}

The theory of authentic leadership is viewed as an extension from transformational leadership [8], where leaders with genuine transformational styles share similar dimensions of transformational exhibit. Authentic leadership theory is later expanded by Yukl and Mahsud [63] who stated that this theory determines the positive dimensions of transformational, ethical, charismatic, and spiritual leadership theories. Authentic leaders are defined as a "moral agent" who empowers followers to take actions that are fair, noble and legitimate [39]. Luthans, Norman, Avolio, and Avey [36] defined the leaders' style as actions derived from an established organizational context equipped with positive psychological capital, creating positive self-regulated behavior that motivates subordinates to foster positive self-development and self-awareness. Based on past empirical studies, leaders' behaviours 
have a significant impact on work attitudes [5, 64] that create better employee behavior and performance (e.g. [27]).

Employee work engagement is considered today a key force for organizational success. Many organizations take the initiative to increase their employee motivation through 'employee engagement strategies' and one of the successful strategies to getting employees engaged is through leader behaviors. Work engagement is defined as "a positive, fulfilling, work-related state of mind characterized by vigor, dedication, and absorption" [50, p. 74]. Vigor refers to "high levels of energy and mental resilience while working and by the willingness and ability to invest effort in one's work" [50, p. 74]. Dedication resembles involvement and is conceptualized as a psychological identification one has with his/her job [50] while absorption is associated with intrinsic enjoyment, while losing self-consciousness at work [2]. According to Schaufeli and Bakker [51], vigor and dedication are the "core dimensions" of engagement. However, Langelaan et al. [34] argue that absorption may be regarded as a consequence of elevated work engagement.

Although past studies have been actively identified the influence of individual elements of work engagement on employee attitudes and behaviours (e.g. [35]), this study will examine how the impact of authentic leaders on overall employee work engagement. Using COR theory, the current study views support from a leader as a form of social support that is "a resource to the extent that they provide or facilitate the preservation of valued resources, but they also can detract from individuals' resources" [21, p. 517]. When employees view positively on their supervisor's leadership, it will have a positive influence on their work engagement. To be specific, employees will have high levels of vigor that demonstrate willingness and persistence, dedicated to achieving goals while immersing themselves in their work; the combination of individual elements represents a high level of work engagement. Past studies have found that employees are more engaged in their work when working with leaders who are perceived as authentic [19]. On the other hand, when employees perceive their leader's style or behavior to be harmful where leaders are untrustworthy and practicing unfair practices, these traits are completely inverse as authentic leader, thus, these negative traits will bring negative impact on work engagement. Employees find no reason to be vigor, dedicated and absorbed into their work assignments. Therefore, it is hypothesized that:
H1: Perceived authentic leadership is positively related to employee work engagement.

\subsection{Life well-being, workplace well-being, and psychological well-being as mediators}

Employee well-being is basically "a pleasurable or positive emotional state resulting from the appraisal of one's job or job experiences" [14, p. 1300]. Understanding the importance of well-being, Rahimnia and Sharifirad [45] suggested researchers to examine the different dimensions of well-being to expand the knowledge and depth in this field. Page and Vella-Brodrick [42] discussed employee well-being as being theoretically divided into job satisfaction, psychological well-being, subjective well-being, and work-related affect. Although there has been scale developed based on multidimensional of employee well-being [65], little empirical research has been conducted to examine the extent to which these three dimensions-life, workplace and psychological influence the perceived authentic leader-work engagement relationship. The description of each well-being dimension is discussed as below:

Life well-being - one's happiness towards life in the absence of negative emotions - is a more appropriate variable than subjective well-being an individual's evaluation of life based on his/her personal standard quality of life [12] — in measuring job satisfaction [65]. Using subjective well-being alone to measure job satisfaction, as what previous researchers have done, is insufficient [61]. It is undeniable that job satisfaction contributes to the overall life satisfaction. However, in psychology literature, researchers found that life satisfaction is only part of job satisfaction [42].

Workplace well-being is defined as satisfaction of work and work-related affect [65]. Of the three dimensions of employee well-being, workplace well-being is the most widely studied. Multinational organizations particularly emphasize on the implementation of practices that enhance workplace well-being in the work environment involved with various stakeholders such as employees, customer, suppliers, and others [25], and claim that workplace well-being affects work stress and job satisfaction.

Psychological well-being includes the purpose of life, acceptance of one's self, the mastery of the physical environment, positive relationships, freedom, and self-growth [49]. Some researchers claimed that psychological well-being shares the same meaning as subjective well-being [42], while others viewed 
them as distinctive constructs [48]. Among other dimensions of well-being, empirical studies on psychological well-being at the workplace are generally limited [40].

Based on each of the above dimensions of well-being, employee well-being was used primarily to measure job satisfaction [58] and many researchers on leadership behaviour often conceptualize employee well-being as job satisfaction [27]. Although past studies have found a significant relationship between leadership behavior and employee job satisfaction, employee well-being is multidimensional and not solely job satisfaction [65], so it may not have the same effect with leader behavior. Authentic leaders are believed to nurture positive self-development in subordinates and potential leaders [4], provide self-awareness and self-regulation components [17], be transparent and clear on their own values and beliefs [66], that could enhance the well-being of employees in organizations [18]. For instance, providing autonomy as part of betterment of employee well-being shows that leaders see their subordinates as capable of determining and regulating their own pattern of doing things. Leaders that are transparent with employees encourage the formation of trusting and identified relationships and increase personal growth (cf. [26]).

Based on the above discussion, it is undeniable that concern about employee well-being should be one of the key characteristics of authentic leaders and past researchers have found that employees exposed to activities that emphasize employee wellbeing report better employee attitudes and behaviors such as higher job satisfaction and commitment [11], and lower intention to leave the organization [38]. Having perception that their leaders are authentic are insufficient because higher work engagement will be realized only when employees see consistency that authentic leader provide environments that fulfil their workplace, life or psychological well-being. Leaders who provide a good working environment for their employees can create workplace well-being for the employees resulting in employee engagement. Working with trusted leaders can indirectly promote psychological well-being as employees experience positive relationships and genuine care from their leaders where they truly feel free to express their ideas and thoughts without concealing themselves. As previously defined, life-well-being refers to one's happiness towards life in which an individual's quality of life is assessed. When employees feel their quality of life is compromised by the pres- sure to obey their leaders, their work engagement may be affected. Therefore, the extent to which the relationship between perceived of authentic leader and employee engagement may be influenced by employee well-being.

In general, there is limited research conducted specifically on the relationship between authentic leadership and employee well-being [45]. By integrating COR theory and the relational perspective, the current study proposes that high perception of authentic leadership in the workplace would impact employee well-being and in turn, employee work engagement. COR theory indicates that individuals feel threatened when there are insufficient resources to fulfil the demand and completion of tasks. In this case, when employees perceive their leaders as not being supportive (loss of resource), this may lead to a lower level of cognitive performance at the workplace [9] and hence, lower level of work engagement. However, lack of perceived authentic leadership alone is insufficient in influencing employee attitudes. From the relational perspective, when employees also have a consistent negative experience of compromising their well-being in the organization, then the negative outcomes are worsened. Conversely, employees who perceive their supervisors' leadership style positively and do not perceive their well-being as being compromised at the workplace would be more engaged in their job. The consistent perception of employees towards their supervisors' leadership style and their own well-being can affect their work engagement. Employees working in SMEs have higher sense of ownership because of their high quality of interpersonal relationship with their leaders as compare to those working in large firms (e.g. [16]). The high quality of interpersonal relationships can enhance the noble characteristics of an authentic leaders in which SME leaders are expected to have self-awareness, trustworthiness and concerns about employees that can promote employee well-being and in turn, their engagement in the workplace. As such, the relationship of perceived authentic leadership on work engagement is mediated by employee well-being (life, workplace, and psychological). It is hypothesized that:

H2: Life well-being mediates the relationship between perceived authentic leadership and work engagement.

H3: Workplace well-being mediates the relationship between perceived authentic leadership and work engagement. 
H4: Psychological well-being mediates the relationship between perceived authentic leadership and work engagement.

\section{Methods}

\subsection{Data collection and respondents' profile}

Data was collected from a two-wave survey. Respondents to the study's survey were recruited using snowball sampling, whereby one respondent refers another to participate. A total of 150 full-time employees working at various SME services sector in the Klang Valley, Malaysia participated in both surveys. The variables such as perceived authentic leadership and employee well-being were collected at Time 1, while the dependent variables such as employee work engagement at Time 2 (i.e. three months after Time 1). As the survey was multi-wave, the respondents were provided unique account ID at Time 1. The purpose of the unique account ID was to match their responses with Time 2 data. Employees in Klang Valley were recruited as this location was estimated to have 4.2 million jobs [29]. The current study considered the importance of understanding the wellbeing of urban employees working in the services sector of these locations.

The survey's respondents consisted of 82 men $(54.67 \%)$ and 68 women $(45.33 \%)$. In terms of age, the majority of respondents $(56 \%)$ were aged between 18 to 24 years. For the other age groups, $32.67 \%$ of respondents were between 25 to 34 years, $8 \%$ between 35 to 44 years, and only one participant $(0.67 \%)$ was between 55 to 65 years. No respondent was over 65 years old but there were
2.66\% participants who did not respond to this item. In terms of personal income, $18 \%$ of respondents earned a monthly income less than RM 2000, 54.67\% earned between RM 2000 to RM 4000, 18.6\% earned between RM 4001 to RM 6000, and 8.67\% earned more than RM 6000. There were $0.06 \%$ participants did not attempt to this item. More than half of the respondents $(65.33 \%)$ hold an executive-level positive, $15.33 \%$ hold a management-level position, while $13.33 \%$ hold a senior executive-level position. The remaining $2.67 \%$ of respondents are C-Suite executives and a total of $3.34 \%$ participants did not respond to this item. In terms of duration of current employment, $48.67 \%$ of respondents have been working in their current organization for less than a year, 28\% between one to two years, $10.67 \%$ between two to five years, and $12.66 \%$ for more than five years.

\subsection{Measurements}

Sixteen items measuring perceived authentic leadership were adapted from Neider and Schriesheim [39] study. These items were measured using a 7-point Likert scale ranging from 1= "Strongly Disagree" to $7=$ "Strongly Agree". Sample items included "My leader solicits feedback for improving his/her dealings with others" and "My leader carefully listens to alternative perspectives before reaching a conclusion". The alpha coefficient of this scale is shown in Table 1.

Employee well-being comprising the dimensions of life, workplace, and psychological were measured using [65] scale. Similarly, the scale's items were also measured using a 7-point Likert scale. Sample items included "I am in a good life situation" (life well-being), "I feel basically satisfied with my work

Table 1

Mean, standard deviation, and bivariate correlation of the variables

\begin{tabular}{|c|c|c|c|c|c|c|c|c|c|c|c|c|}
\hline Variables & Mean & SD & 1 & 2 & 3 & 4 & 5 & 6 & 7 & 8 & 9 & 10 \\
\hline 1. Gender & 1.45 & 0.50 & - & & & & & & & & & \\
\hline 2. Age & 1.59 & 0.80 & 0.078 & - & & & & & & & & \\
\hline 3. Personal income & 2.18 & 0.83 & -0.053 & $0.545^{* *}$ & - & & & & & & & \\
\hline 4. Position level & 1.65 & 1.03 & -0.078 & $0.385^{* *}$ & $0.350^{* *}$ & - & & & & & & \\
\hline 5. Duration of current employment & 1.87 & 1.04 & 0.085 & $0.682^{* *}$ & $0.523^{* *}$ & $0.388^{* *}$ & - & & & & & \\
\hline 6. Perceived authentic leadership & 4.80 & 1.24 & $0.196^{*}$ & 0.043 & 0.040 & -0.035 & $0.175^{*}$ & 0.973 & & & & \\
\hline 7. Life well-being & 4.73 & 1.15 & $0.203^{*}$ & $0.222^{* *}$ & $0.266^{* *}$ & 0.154 & $0.227^{* *}$ & $0.489^{* *}$ & 0.898 & & & \\
\hline 8. Workplace well-being & 4.68 & 1.26 & $0.253^{* *}$ & $0.204^{*}$ & $0.200^{*}$ & 0.089 & $0.318^{* *}$ & $0.624^{* *}$ & $0.663^{* *}$ & 0.915 & & \\
\hline 9. Psychological well-being & 5.13 & 0.98 & 0.031 & 0.135 & 0.144 & 0.067 & $0.201^{*}$ & $0.363^{* *}$ & $0.574^{* *}$ & $0.513^{* *}$ & 0.805 & \\
\hline 10. Work engagement & 4.75 & 1.25 & $0.244^{* *}$ & 0.116 & 0.094 & 0.091 & $0.246^{* *}$ & $0.745^{* *}$ & $0.644^{* *}$ & $0.845^{* *}$ & $0.549^{* *}$ & 0.871 \\
\hline
\end{tabular}

Note: $\mathrm{N}=150 .{ }^{*} p<0.05 ;{ }^{* *} p<0.01$. Boldface italics along the diagonal represent the Cronbach's alpha values. 
achievements in my current job" (workplace wellbeing), and "People think I am willing to give and to share my time with others" (psychological wellbeing). The alpha coefficients of this scale are above 0.70 .

Six items from Schaufeli, Salanova, GonzálezRomá, and Bakker [50] that targeted on employee vigor were used to measure employee work engagement. The scale's reliability in this study was 0.871 . Items measurement on vigor were used as the aim of this study is to analyze whether the extent to which their perceptions of the leader's authenticity influence their vigor, their effort in their work. Vigor or vitality is used interchangeably and both are the basis of work life and the general theoretical equation of work activity [6]. In addition to a 7-point Likert scale, close-ended questions were also asked. Sample items included "When I get up in the morning, I feel like going to work." and "At my work I always persevere, even when things do not go well."

General demographic data was also collected gender $(1=$ male, 2 =female), age (four categories), personal income (four categories), position level (four categories), and duration of current employment (four categories). These variables were treated as control variables and held constant as they could have potential effects on the studied variables. Past research has produced mixed results regarding the relationship between demographic variables and employee well-being (cf[15, 52]. Therefore, the current study included these demographic variables as control variables for data analysis.

\section{Results}

\subsection{Preliminary analyses}

As the survey's items were self-rated, data collected may be subjected to common method variance. Self-report surveys have the potential to be inflated and in turn, create a bias tendency for the hypothesized relationships [43]. The current study conducted a series of confirmatory factor analyses to remedy this bias tendency and attest to the possible issue of common method variance. To ensure relevance of model, the proposed model was determined using an appropriate combination of absolute, incremental, and parsimony fit indexes as benchmarks (see Table 2). The proposed five-factor model perceived authentic leadership, life well-being, workplace well-being, psychological well-being, and work engagement - showed an acceptable fit $\left(\chi^{2} / d f\right.$ value $=1.69 ; \mathrm{TLI}=0.927 ; \mathrm{IFI}=0.940 ; \mathrm{CFI}=0.939$; RMSEA $=0.068$ ). In addition, this study demonstrated convergent validity and all factor loadings were statistically significant.

Four alternative models (i.e. four-factor model, three-factor model, two-factor model, and one-factor model) were compared and checked for discriminant validity. Results of the confirmatory factor analysis show that the four alternative models produce poor data fit, as presented in Table 1, in comparison to the five-factor model. These results support the discriminant validity of the five-factor model show. Additional tests suggested by Podsakoff et al. [43] such as the single-common-method-factor approach, were used to verify the presence of common method variance. An unmeasured method factor was added into the loading of the five-factor model. The results showed that a $\chi^{2}$ difference test explained that the proposed five-factor model demonstrated better data fit since the unmeasured method factor in the five-factor model does not lead to a significant increase in the model fit $(\Delta \times 2(\Delta d f)=399.71$ (219), $p<0.001 ; \mathrm{CFI}=0.909$; $\mathrm{TLI}=0.900 ; \quad \mathrm{IFI}=0.910 ; \quad \mathrm{RMSEA}=0.070)$. This series of confirmatory factor analyses confirmed that the study's proposed model meets the criteria for discriminant validity and independence of measures and hence, exhibit minimal risk of common method variance.

\subsection{Hypothesis testing}

Table 2 shows the mean, standard deviation, and bivariate correlation of the variables. The relationships among the variables can be seen from the bivariate correlations. The results show the mean scores of psychological well-being to be higher than workplace well-being. In general, all correlations are below 0.70 with the exception of the correlation between perceived authentic leadership and work engagement $(r=0.745, p<0.01)$ and the correlation between workplace well-being and work engagement $(r=0.845, p<0.01)$. These results indicate low possibility of multicollinearity in the regression apart from the two correlational paths higher than 0.70 [56]. In addition, the effects of the demographic variables were controlled. The results showed the variance inflation factor (VIF) value of all paths to be less than 3 but greater than 0.10 , further indicating the low risk of multicollinearity in this study. 
Table 2

Comparison among measurement models

\begin{tabular}{lcccccc}
\hline Model & $\chi 2(d f)$ & $\Delta \chi 2$ & CFI & TLI & IFI & RMSEA \\
\hline Full measurement model (five factors) $^{\prime}$ & $659.59(390)$ & - & 0.939 & 0.927 & 0.940 & 0.068 \\
Four-factor model $^{\mathrm{a}}$ & $799.39(424)$ & $139.8^{* * *}$ & 0.915 & 0.907 & 0.916 & 0.077 \\
Three-factor model $^{\mathrm{b}}$ & $977.16(427)$ & $177.77^{* * *}$ & 0.875 & 0.864 & 0.876 & 0.093 \\
Two-factor model $^{\mathrm{c}}$ & $1050.96(429)$ & $73.79^{* * *}$ & 0.859 & 0.847 & 0.860 & 0.099 \\
One-factor model $^{\mathrm{d}}$ & $1664.97(430)$ & $614.02^{* * *}$ & 0.720 & 0.698 & 0.723 & 0.139 \\
Five-factor model with an unmeasured method factor $^{*}$ & $1059.30(609)$ & $399.71^{* * *}$ & 0.909 & 0.900 & 0.910 & 0.070 \\
\hline
\end{tabular}

Note: $\mathrm{N}=150,{ }^{* * *} p<0.001 ; \chi^{2}$, chi-square discrepancy; $d f$, degrees of freedom; CFI, comparative fit index; TLI, Tucker-Lewis index; IFI,

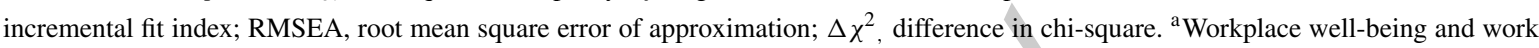
engagement combined into a single factor. ${ }^{\text {b}}$ Workplace well-being, work engagement, and psychological well-being combined into a single factor. ${ }^{\mathrm{c}}$ Workplace well-being, work engagement, psychological well-being, and life well-being combined into a single factor. ${ }^{\mathrm{d}}$ Harman's single-factor model where all are variables are combined into a single factor.

The study's hypotheses comprising direct, indirect, and total effects of perceived authentic leadership on work engagement were estimated by Hayes and Preacher [20] PROCESS macro for SPSS, with a bootstrapped of 5000 alternative samples and a confidence interval (CI) of 95\%. Structural equation modeling was not chosen for data analysis as it requires the ratio of number of respondents to estimated number of parameters to be greater than 1:20 [30]. Since the number of parameters in the proposed model is large but overall sample size small, PROCESS macro for SPSS was used instead. In addition, normality of the sampling distribution and the significant paths of A and B as stated by Baron and Kenny [7] were not required.

Based on Hayes and Preacher [20] method, the links in the mediation model are separated. Path A represents the direct effect between the independent variable (IV) and mediating variable (MV) while the effects of other variables are controlled. Path B represents the direct effect between the MV and dependent variable (DV) while Path C' represents the direct effect between the IV and DV. The indirect effect, also known as the mediating effect, are the results of Paths A and B. Path C represents the total effect between the IV and DV, where it is a combination of direct and indirect effects [44].

Table 3 shows the effects and paths among the variables. H1 posited that perceived authentic leadership is positively related to work engagement. This hypothesis is supported as the results indicate a significant effect between both variables (Path C'; $\beta=0.338, p<0.001$ ).

The results of Path A were supported as perceived authentic leadership is significantly related to all dimensions of employee well-being. Among the dimensions, workplace well-being demonstrated the highest effect $(\beta=0.579, p<0.001)$. On the other hand, the results of Path B indicated only life wellbeing has no significant effect on work engagement ( $\beta=0.064, p>0.01)$ although workplace well-being $(\beta=0.531, p<0.001)$ and psychological well-being $(\beta=0.159, p<0.01)$ have a significant effect on work engagement.

The total effect (Path C) shows perceived authentic leadership to have a significant effect on work engagement. However, when indirect effects were eliminated from the total effect (Path C'), the effect of perceived authentic leadership on work engagement is still significant but with a reduced magnitude. This indicates that inclusion of employee well-being intervenes the linkage between perceived authentic leadership and work engagement. Bootstrapped analysis for indirect effects in Table 3 shows that perceived authentic leadership has a significant effect on work engagement when workplace well-being included between the two variables. The results show that only workplace well-being played the role of mediating variable in this relationship. The indirect effect of workplace well-being accounts for $81 \%$ of the total effect whereas the indirect effects of life well-being and psychological well-being only account for $7 \%$ and $12 \%$ respectively. Thus, $\mathrm{H} 3$ is supported while $\mathrm{H} 2$ and $\mathrm{H} 4$ are not.

\subsection{Auxiliary analysis}

Given mixed results where only workplace dimension mediates, but not the dimensions of life and psychological associated with perceived authentic leadership-work engagement linkages, additional analysis was conducted to analyse what people are 
Table 3

Mediation results with work engagement as the dependent variable

\begin{tabular}{lcccccc}
\hline IV & MV & $\begin{array}{c}\text { Total } \\
\text { effect } \\
\text { (Path C) }\end{array}$ & $\begin{array}{c}\text { Effect of IV } \\
\text { on MV } \\
\text { (Path A) }\end{array}$ & $\begin{array}{c}\text { Effect of MV } \\
\text { on DV } \\
\text { (Path B) }\end{array}$ & $\begin{array}{c}\text { Direct } \\
\text { effect } \\
\text { (Path C') }\end{array}$ & $\begin{array}{c}\text { Indirect } \\
\text { effect }\end{array}$ \\
\hline AL & & & & $0.338^{* * *}$ & \\
& $0.718^{* * *}$ & & & & $-0.169 / 0.099$ \\
& & $0.435^{* * *}$ & 0.064 & & $0.117 / 0.298$ \\
& WWB & & $0.579^{* * *}$ & $0.531^{* * *}$ & & $-0.023 / 0.029$ \\
\hline
\end{tabular}

Note: $F(9,140)=68.75, p<0.001, \mathrm{R}^{2}=0.81$; IV, independent variable; $\mathrm{MV}$, mediating variable; $\mathrm{DV}$, dependent variable; AL, perceived authentic leadership; LWB, life well-being; WWB, workplace well-being; PWB, psychological well-being; lower CI corresponding to the indirect effect is on the left separated by slash (/) while upper CI corresponding to indirect effect is on the right; ${ }^{* *} p<0.01,{ }^{* * *} p<0.001,95 \%$ CI.

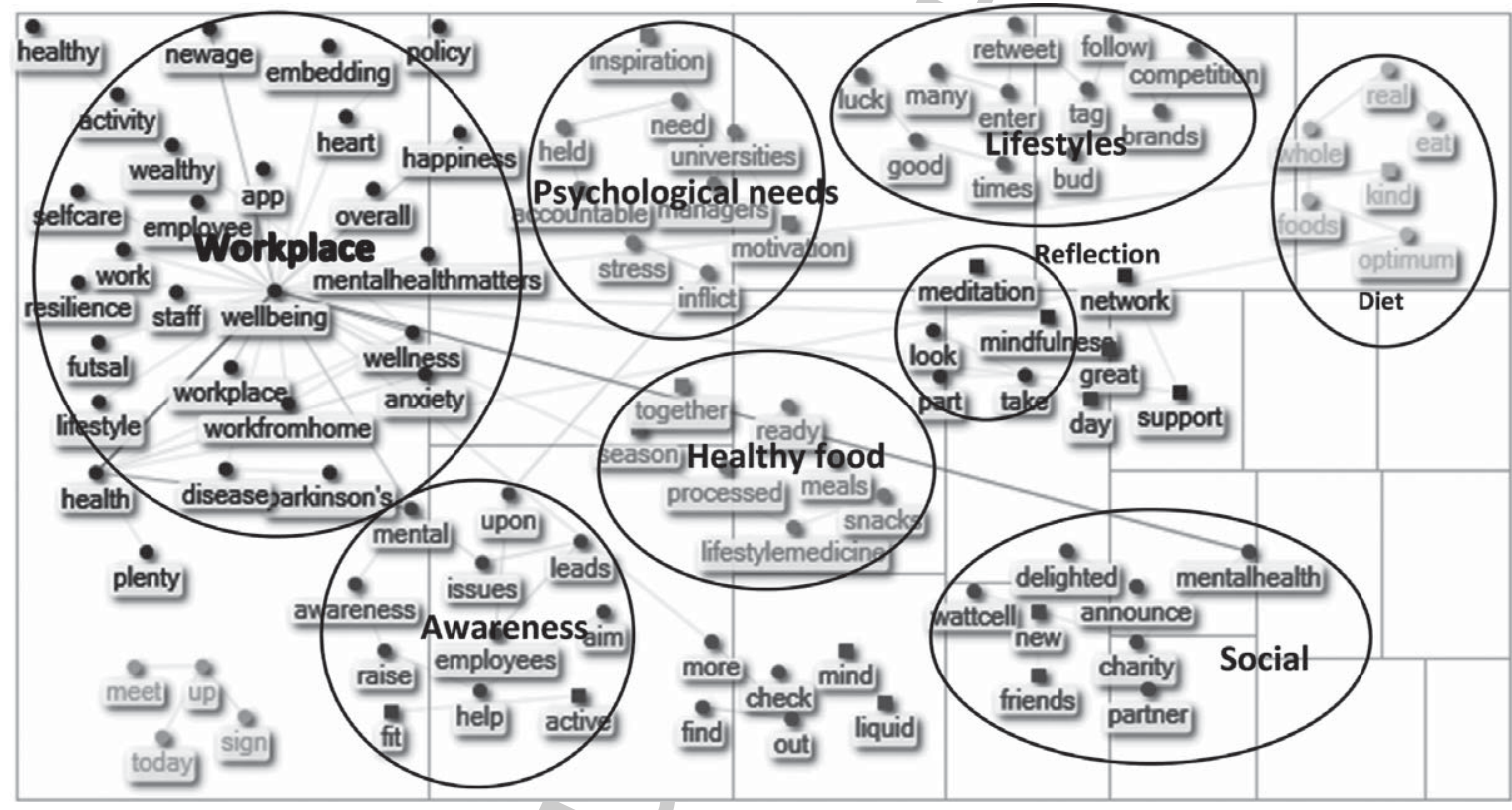

Fig. 2. The Twitter's semantic network of well-being.

seeing or making judgments about the well-being. NodeXL software was used to analyse Twitter data using semantic analysis. Data from micro blogs such as Twitter has been used because any information or opinion about well-being is largely organized and shared through hash tags with symbol \#. Hash tags are community-driven practices to put other factors and metadata into tweets by promoting folksonomy. This social media contains a large number of sentiment-embodied sentences. Sentiment is described as personal beliefs or judgments that are not based on evidence or certainty [53], which may reflect the emotional state of the user, which can provide information about well-being. This study explores the semantic networks using the function of word pairs in NodelXL. Twitter data was collected to 18000 tweets from all individuals who recently used "\#wellbeing" in their tweets. Figure 2 shows that there are eight primary themes found: workplace, lifestyles, psychological need, awareness, social, healthy foods, diet and reflection. Comparing the main theme in the semantic network, two major findings are obtained. First, workplace theme is the central of well-being. It contains maximum vertices in the connected component ( 27 words) where happiness, mental, health, work from home and employees are a few words that are connected to the workplace theme. It is interesting to note that the semantic network results share simi- 
lar ideas of workplace well-being in this study where these words affect or being affect by employees. Second, the lifestyles theme and psychological themes are the second and third major themes in components with 11 words and 9 words respectively. The words or nodes under the Lifestyles theme are lifestyle, good, luck, retweet, bud and tags while the words for psychological theme include stress, inflicted, managers, and accountable. Overall, it is important to note that the three themes defined by social media are the three dimensions of well-being measured in this study.

\section{Discussion}

In general, the current study demonstrated how perceived authentic leadership is related to work engagement through employee well-being, particularly the dimension of workplace well-being. All the research hypotheses were validated except for $\mathrm{H} 2$ and $\mathrm{H} 4$ which expected life well-being and psychological well-being to also mediate the relationship between perceived authentic leadership and work engagement. Perceived authentic leadership affects the work engagement of employees in Klang Valley, Malaysia both directly and indirectly through workplace well-being. In the additional analysis conducted in this study, the results of the semantic network analysis indicate that workplace is a key principle of the definition of well-being as twitter users discuss more workplace issues using their social media. These results may explain why only workplace well-being hypothesis is supported except for other dimensions.

Most studies assume that leadership styles which are employee-oriented motivate employees and produce positive work-related outcomes(e.g. [31, 37]) but limited studies on employee engagement [27]. Hence, the results from the current study can be deemed as novel findings. As hypothesized (H1), higher levels of perceived authentic leadership lead to increases in work engagement. This finding implies that organizational leaders viewed as having authentic leadership characteristics (e.g. promote self-development, self-awareness, and trust in employees) result in more engaged employees at the workplace; a possible avenue for managers and supervisors to take note of.

The results from the current study indicate the importance of improving employee well-being, particularly workplace well-being, as it increases engagement at work. The results indicate that fulfilling life well-being at the workplace is not a priority to achieve work engagement, which is in line with findings from [65] who used life well-being instead of subjective well-being to explain the concept of one's happiness in life. When employees perceived to have fulfilled with life or thinking their way of life is now fun and good, additional practices that generate well-being of life do not have an impact on work engagement. In short, the current findings suggest that to improve work engagement, organizations should pay more attention to workplace well-being. By creating more meaningful employment, increasing employee confidence, and sharing, it strengthens engagement and prevent loss of resources. For example, human resource practitioners should design the work in a way that increases workplace well-being, whereby employees feel their work to be important to themselves and the organization.

The relationship between perceived authentic leadership and job satisfaction was also found to be mediated by workplace well-being (H3). The finding is consistent with past research on workplace wellbeing where this type of well-being has a profound effect on employees' work attitudes and productivity [25]. Life and psychological well-being were not found to be mediators and these results could reflect past researchers' claims that the distinction between these two variables is not clear-cut [48]. That being said, the findings from the current study support the claim that employee well-being is not a single factor and should be holistically tested by assessing each of its dimension separately. These findings validate the three dimensions of employee well-being developed by Zheng et al. [65]. Ironically, semantic network analysis allows us to identify three key themes about how Twitter users describe well-being through words where their words and expression through words are clustered. The results of the three main themes are similar to the three dimensions used in this study. This clearly shows that well-being of employees is multifaceted and should not be combined into one common dimension. As a result, this study has attempted to study examine the three dimensions of employee well-being.

\section{Limitations and suggestions for future research}

The current study is not without limitations. Although the survey data were collected at two different times, all items in the survey were self-rated. While self-reported surveys are subjected to common 
method variance and inflation in correlational values [43], the current study has countered these issues by including an unmeasured method factor consisting of six items unrelated to the variables studied. Besides that, the survey only assessed these variables from the viewpoint of employees from various SME services sectors in Malaysia, which are subjective. In addition, this study recruited respondents via snowball sampling as the sampling method. This method could result in collecting data from only a small subgroup of similar employees. This could render the results as not generalizable to population groups that differ from this subgroup. In addition to using quantitative method to correct for bias tendencies, this study sought to examine whether there was a pattern of similarity between social media and the self-assessment of well-being. Future research could collect data from multiple sources such as organizational leaders to generate a more wholesome assessment of authentic leadership. It would be interesting to see whether authentic leadership as perceived by employees and leaders will be vastly different. Future research could also examine other objectively measured variables such as actual performance and work productivity.

Furthermore, the items measuring employee wellbeing were adopted from Zheng et al. [65], a study that was conducted in China. Cultural differences could still exist although Malaysia and China are usually known as having a similar collectivistic culture. Cultural differences could affect the structure and validity of the scale used. From the semantic network analysis conducted in this study, the theme derived share characteristic similar to the scale of employee well-being used in this study. It should be noted that the qualitative data collected is all about word and expressions through the words in written English. Therefore, the cross-cultural generalization of results is important and future research could explore further how differences in culture and languages used may affect the relationship between perceived authentic leadership and job satisfaction as mediated by employee well-being.

The results from the current study indicated that only workplace well-being mediates the relationship between perceived authentic leadership and job satisfaction. Future research should investigate other contextual factors that could affect this relationship. Furthermore, as the current study was a cross-sectional one, these results do not confirm causality. Future research should consider collecting data across different time periods (i.e. longitudinal study), industries, and geographical locations.
As aforementioned, the current study considered demographic variables - gender, age, personal income, position level, and duration of current employment - as control variables and hence, their relationships with perceived authentic leadership, employee well-being, and employee engagement were not examined. Holvino [23] claimed that it is imperative for future studies to address the simultaneity of gender, age, and position level in an organization. Although literature often recognizes the effects of socio-demographic variables on well-being (e.g. [13]), these variables are usually regarded as control variables and the extent of their impact is rarely examined [60]. Hence, future research is encouraged to explore the effects of these demographic variables on employees' perception of authentic leadership, employee well-being, and employee engagement.

In summary, the findings of the current study provide a strong framework on how authentic leadership impacts employee engagement both directly and indirectly through employee well-being. As not all dimensions of employee well-being were found to have an impact on the studied relationship, either directly or as a mediator, it is important for researchers to distinguish the different dimensions when examining employee well-being. The findings of the current study imply that leaders should adopt an authentic leadership style and provide support for work-life balance which improves employee wellbeing at the workplace. This integrated conceptual framework provides an avenue for human resource practitioners to explore that would promote employee engagement among employees.

\section{Conflict of interest}

On behalf of all authors, the corresponding author states that there is no conflict of interest.

\section{References}

[1] Abbas W, Wu W. Employee engagement. fairness and trust: An empirical assessment. Human Systems Management. 2018;37(3):287-97.

[2] Alarcon GM, Edwards JM, Menke LE. Student burnout and engagement: A test of theconservation of resources theory. The Journal of Psychology. 2011;145(3):211-27.

[3] Avolio BJ, Gardner WL, Walumbwa FO, Luthans F, May DR. Unlocking the mask: A look at the process by which authentic leaders impact follower attitudes 
and behaviors. The Leadership Quarterly. 2004;15(6): 801-23.

[4] Avolio BJ, Gardner WL. Authentic leadership development: Getting to the root of positive forms of leadership. The Leadership Quarterly. 2005;16(3):315-38.

[5] Azanza G, Moriano JA, Molero F. Authentic leadership and organizational culture as drivers of employees' job satisfaction. Revista de Psicología del Trabajo y de las Organizaciones. 2013;29(2):45-50.

[6] Bakker AB, Schaufeli WB, Leiter MP, Taris TW. Work engagement: An emerging concept in occupational health psychology. Work \& Stress. 2008;22(3):187-200.

[7] Baron RM, Kenny DA. The Moderator- Mediator Variable Distinction in Social Psychological Research: Conceptual. Strategic, and Statistical Considerations. Journal of Personality and Social Psychology. 1986;51(6):1173-82.

[8] Bass BM, Steidlmeier P. Ethics, character, and authentic transformational leadership behavior. The Leadership Quarterly. 1999;10(2):181-217.

[9] Baumeister RF, Twenge JM, Nuss CK. Effects of social exclusion on cognitive processes: anticipated aloneness reduces intelligent thought, Journal Of Personality And Social Psychology. 2002;83(4):817.

[10] Borgersen HC, Hystad SW, Larsson G, Eid J. Authentic leadership and safety climate among seafarers, Journal of Leadership and Organizational Studies. 2014;21(4):394402.

[11] Butts MM, Casper WJ, Yang TS. How important are work-family support policies? A meta-analytic investigation of their effects on employee outcomes. Journal of Applied Psychology. 2013;98(1):1-25.

[12] Diener E. Subjective well-being: The science of happiness and a proposal for a national index. American Psychologist. 2000;55(1):34-43.

[13] Diener E, Suh EM, Lucas RE, Smith HL. Subjective wellbeing: Three decades of progress. Psychological Bulletin. 1999;125(2):276-302.

[14] Dunnette MD. Handbook of industrial and organizational psychology. Chicago: Rand McNally. (1976).

[15] Eby LT, Casper WJ, Lockwood A, Bordeaux C, Brinley A. Work and family research in IO/OB: Content analysis and review of the literature (1980-2002). Journal Of Vocational Behavior. 2005;66(1):124-97.

[16] Galabova L, McKie L. The five fingers of my hand": human capital and well-being in SMEs, Personnel Review. 2013;42(6):662-83.

[17] Gardner WL, Avolio BJ, Walumbwa FO. Authentic leadership development: Emergent trends and future directions. In Gardner WL, Avolio BJ, Walumbwa FO. (Eds.), Authentic Leadership Theory and Practice: Origins, Effects And Development: 387-406. Oxford, UK: Elsevier Science. (2005)

[18] Gardner TM, Wright PM, Moynihan LM. The impact of motivation, empowerment, and skill-enhancing practices on aggregate voluntary turnover: The mediating effect of collective affective commitment. Personnel Psychology. (2001);64(2):315-50.

[19] Giallonardo LM, Wong CA, Iwasiw CL. Authentic leadership of preceptors: predictor of new graduate nurses' work engagement and job satisfaction. Journal of Nursing Management. (2010);18(8):993-1003.
[20] Hayes AF, Preacher KJ. Statistical mediation analysis with a multicategorical independent variable. British Journal of Mathematical and Statistical Psychology. 2014;67(3): 451-70.

[21] Hobfoll SE. Conservation of resources: A new attempt at conceptualizing stress. American Psychologist. 1989;44(3):513-24.

[22] Hobfoll SE. Conservation of resources and disaster in cultural context: The caravans and passageways for resources. Psychiatry. 2012;75(3):227-32.

[23] Holvino E. Intersections: The simultaneity of race, gender and class in organization studies. Gender Work and Organization. 2010;17(3):248-77.

[24] Hsieh CC. Wang DS. Does supervisor-perceived authentic leadership influence employee work engagement through employee-perceived authentic leadership and employee trust? The International Journal of Human Resource Management. 2015;26(18):2329-48.

[25] Hyett MP, Parker GB. Further Examination of the Properties of the Workplace Well-Being Questionnaire (WWQ), Social Indicators Research. 2015;124(2):683-92.

[26] Ilies R, Morgeson FP, Nahrgang JD. Authentic leadership and eudaemonic well-being: Understanding leader-follower outcomes. The Leadership Quarterly. 2005;16(3):373-94.

[27] Inceoglu I, Thomas G, Chu C, Plans D, Gerbasi A. Leadership behavior and employee well-being: An integrated review and a future research agenda. The Leadership Quarterly. 2018;29(1):179-202.

[28] Kemmerer KP. Talent is Never Enough: Discover the Choices that Will Take You Beyond Your Talent. MEIEA Journal. 2014;14(1):308-9.

[29] The Klang Valley has finally arrived to be in a top spot in world business. Retrieved from https://www.thestar.com.my/news/nation/2013/01/02/theklang-valley-has-finally-arrived-to-be-in-a-top-spot-inworld-business/ (2013)

[30] Kline RB. Principles and practice of structural equation modeling (3 ed.): Guilford Press. (2011)

[31] Koch AR, Binnewies C. Setting a good example: Supervisors as work-life-friendly role models within the context of boundary management. Journal of Occupational Health Psychology. 2015;20(1):82.

[32] Kossek EE, Pichler S, Bodner T, Hammer LB. Workplace social support and work-family conflict: A meta-analysis clarifying the influence of general and work-family-specific supervisor and organizational support. Personnel Psychology. 2011;64(2):289-313.

[33] Kouzes JM, Posner BZ. The five practices of exemplary leadership. The Jossey-Bass Reader on Educational Leadership. 2007;63-74.

[34] Langelaan S, Bakker AB, Van Doornen LJ, Schaufeli WB. Burnout and work engagement: Do individual differences make a difference? Personality and Individual Differences. 2006;40(3):521-32.

[35] Lu L, Lu ACC, Gursoy D, Neale NR. Work engagement, job satisfaction, and turnover intentions. International Journal of Contemporary Hospitality Management. 2016;28(4):737-61.

[36] Luthans F, Norman SM, Avolio BJ, Avey JB. The mediating role of psychological capital in the supportive organizational 
climate-employee performance relationship. Journal of Organizational Behavior. 2008;29(2):219-38.

[37] McCarthy A, Cleveland JN, Hunter S, Darcy C, Grady G. Employee work-life balance outcomes in Ireland: a multilevel investigation of supervisory support and perceived organizational support. The International Journal of Human Resource Management. 2013;24(6):1257-76.

[38] Morrissey TW, Warner ME. An exploratory study of the impacts of an employer-supported child care program. Early Childhood Research Quarterly. 2011;26(3):344-54.

[39] Neider LL, Schriesheim CA. The authentic leadership inventory (ALI): Development and empirical tests. The Leadership Quarterly. 2011;22(6):1146-64.

[40] Nelson K, Boudrias J-S, Brunet L, Morin D, De Civita M, Savoie A, Alderson M. Authentic leadership and psychological well-being at work of nurses: The mediating role of work climate at the individual level of analysis. Burnout Research. 2014;1(2):90-101.

[41] Oh J, Cho D, Lim DH. Authentic leadership and work engagement: the mediating effect of practicing core values. Leadership \& Organization Development Journal. 2018;39(2):276-90.

[42] Page KM, Vella-Brodrick DA. The 'what', 'why' and 'how'of employee well-being: A new model. Social Indicators Research. 2009;90(3):441-58.

[43] Podsakoff PM, MacKenzie SB, Lee J-Y, Podsakoff N. Common method biases in behavioral research: A critical review of literature and recommended remedies. Journal of Applied Psychology. 2003;88:879-903.

[44] Preacherand KJ, Hayes AF. Asymptotic and resampling strategies for assessing and comparing indirect effects in multiple mediator models. Behavior Research Methods. 2008;40(3):879-91.

[45] Rahimnia F, Sharifirad MS. Authentic leadership and employee well-being: The mediating role of attachment insecurity. Journal of Business Ethics. 2015;132(2): 363-77.

[46] Rego A, Sousa F, Marques C, e Cunha MP. Authentic leadership promoting employees' psychological capital and creativity. Journal of Business Research. 2012;65(3):42937.

[47] Renwick D. Line manager involvement in HRM: an inside view. Employee Relations. 2003;25(3):262-80.

[48] Ring L, Höfer S, McGee H, Hickey A, O'Boyle C. Individual quality of life: can it be accounted for by psychological or subjective well-being? Social Indicators Research. 2007;82(3):443-461.

[49] Ryff CD. Psychological well-being in adult life, Current Directions in Psychological Science. 1995;4(4):99-104.

[50] Schaufeli WB, Martinez IM, Pinto AM, Salanova M, Bakker $A B$. Burnout and engagement in university students: A cross-national study. Journal of Cross-Cultural Psychology. 2002;33(5):464-81.

[51] Schaufeli WB, Bakker AB. Job demands, job resources, and their relationship with burnout and engagement: A multi-sample study. Journal of Organizational Behavior. 2004;25:293-315
[52] N. Skinner Pocock B. Flexibility and work-life interference in Australia. Journal of Industrial Relations. 2011;53(1):6582.

[53] Smith MA, Shneiderman B, Milic-Frayling N, Mendes Rodrigues E, Barash V, Dunne C, Capone T, Perer A, Gleave E. Analyzing (social media) networks with NodeXL. In Proceedings of the Fourth International Conference on Communities and Technologies. 2009;255-264.

[54] Sun L-Y, Aryee S, Law KS. High-Performance Human Resource Practices, Citizenship Behavior, and Organizational Performance: A Relational Perspective. The Academy of Management Journal. 2007;50(3):558-77.

[55] C.J. Syrek, E. Apostel Antoni CH. Stress in highly demanding IT jobs: Transformational leadership moderates the impact of time pressure on exhaustion and work-life balance. Journal of Occupational Health Psychology. 2013;18(3):252-61.

[56] Tabachnick BG, Fidell LS. Using multivariate statistics (3rd ed.). New York HarperCollins. (1996).

[57] Koon V-Y, Tee Y-H. When does ostracism lead to turnover intention? The moderated mediation model of job stress and job autonomy. IIMB Management Review. (2019) 10.1016/j.iimb.2019.10.007

[58] Warr P, Cook J, Wall T. Scales for the measurement of some work attitudes and aspects of psychological well-being. Journal of Occupational Psychology. 1979;52(2):129-48.

[59] Whitener EM. Do "high commitment" human resource practices affect employee commitment? A cross-level analysis using hierarchical linear modeling. Journal of Management. 2001;27(5):515-35.

[60] Wilks DC, Neto F. Workplace well-being, gender and age: Examining the 'double jeopardy'effect. Social Indicators Research. 2013;114(3):875-90.

[61] Wright TA, Bonett DG. The contribution of burnout to work performance. Journal of Organizational Behavior. (1997;18(5):491-9.

[62] Wright TA, Quick JC. The role of character in ethical leadership research. The Leadership Quarterly. 2011;22(5): 975-8.

[63] Yukl G, Mahsud R. Why flexible and adaptive leadership is essential. Consulting Psychology Journal: Practice and Research. 2010;62(2):81-93.

[64] S. Zahro, M.C. Wu, N. Hidayati, and E. Prahastuti, Employees' creativity development in Indonesia's fashion sub-sectors, Human Systems Management. 36(1) (2017), 27-39.

[65] X. Zheng, W. Zhu, H. Zhao, and C. Zhang, Employee well-being in organizations: Theoretical model, scale development, and cross-cultural validation. Journal of Organizational Behavior. 36(5) (2015), 621-644.

[66] W. Zhu, D.R. May, and B.J. Avolio, The impact of ethical leadership behavior on employee outcomes: The roles of psychological empowerment and authenticity, Journal of Leadership \& Organizational Studies. 11(1) (2004), 16-26.

[67] M. Zuhaira, Y.-Z. Tian, and A. Karrar Abdulelah. Corporate Commitment, Identification, Ethical Leadership and Social Responsibility.Human Systems Management. 37(3), 345 352. 